\title{
Experiences with Glucagon-Like Peptide-1 Receptor Agonist in Children with Acquired Hypothalamic Obesity
}

\author{
Jiska van Schaik ${ }^{a}$ e $\quad$ Dominique G.A. Begijn ${ }^{a}$ Laura van lersel ${ }^{a}$ \\ Yvonne Vergeer $^{a}{ }^{b}$ Eelco W. Hoving ${ }^{c}$ Babette Peeters $^{d}$ \\ Hanneke M. van Santen ${ }^{\mathrm{a}}$ e \\ aDivision of Pediatric Endocrinology, Wilhelmina Children's Hospital, University Medical \\ Center Utrecht, Utrecht, The Netherlands; ${ }^{b}$ Diabetes Centraal, St Antonius Hospital, \\ Utrecht, The Netherlands; ' ${ }^{C}$ Department of Neurooncology, Princess Máxima Center, \\ Utrecht, The Netherlands; ${ }^{\mathrm{d}}$ Department of Pediatrics, Meander Medical Center, Utrecht,

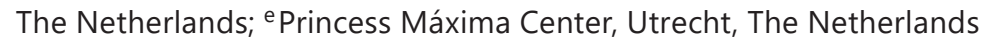

\section{Keywords}

Hypothalamic dysfunction · Obesity · Suprasellar tumor - Glucagon-like peptide-1 receptor agonist

\begin{abstract}
Objective: Hypothalamic obesity $(\mathrm{HO})$ in children after treatment for a tumor in the suprasellar region has severe implications. Previous studies have shown various effects of glucagonlike peptide-1 (GLP-1) receptor agonist in acquired $\mathrm{HO}$, but in adults only. We present our experience of GLP-1 receptor agonist (exenatide) treatment during a 1-year period on body mass index (BMI) in children with acquired HO. Patients and Methods: Children with severe weight gain after treatment for suprasellar tumor were given $2 \mathrm{mg}$ exenatide weekly for a 12 -month period. All had undergone previous dietary intervention. BMI standard deviation score (SDS), weight change, and adverse effects were assessed. Results: Five children with a mean age of 15.4 years (range 13-18) and a mean follow-up time of 8.4 years (mean age of 7.0 years at the time of brain tumor diagnosis) were treated with GLP-1 receptor agonist. After 1 year, BMI SDS or absolute weight had not changed significantly compared to the period without treatment (BMI SDS change $+0.005,95 \% \mathrm{Cl}-0.07$ to $0.08, p=0.89$, and absolute weight change $+1.5 \mathrm{~kg}, 95 \% \mathrm{Cl}-0.08$ to $3.1, p=0.061$ ). Only 1 patient experienced weight loss after 1 year $(-5.4 \mathrm{~kg}, \mathrm{BMI}$ SDS -0.33$)$. All patients experienced mild side effects, such as injection pain or nausea, and 2 patients stopped treatment upon their own request after 8 and 11
\end{abstract}


van Schaik et al.: GLP-1 Receptor Agonist for Hypothalamic Obesity

months, respectively. Conclusions: In this small cohort, we found little effect of GLP-1 receptor agonist in the treatment for acquired $\mathrm{HO}$. Future research should focus on the prevention of $\mathrm{HO}$ or, if prevention is not possible, on alternative, individualized interventions.

(C) 2020 The Author(s)

Published by S. Karger AG, Basel

\section{Introduction}

Hypothalamic dysfunction after treatment for a suprasellar brain tumor may have a profound influence on quality of life in children and adolescents, among others due to a disturbed day-night rhythm, temperature dysregulation, adipsia, panhypopituitarism, and (morbid) hypothalamic obesity (HO) [1-3]. Within all brain tumors, craniopharyngioma is the most common cause of hypothalamic dysfunction, although all suprasellar tumors have the potential to cause hypothalamic dysfunction [4,5]. The 10-year survival of pediatric craniopharyngioma is excellent ( $93 \%$ ), but outcome is often greatly disturbed due to hypothalamic dysfunction, with up to $44-50 \%$ of survivors of childhood craniopharyngioma developing $\mathrm{HO}[6,7]$. HO is a serious complication with often reported resistance against lifestyle interventions and medical treatment [8]. These children are at great risk of developing metabolic syndrome and premature mortality [9]. There is an urgent need to reduce the deleterious impact of acquired $\mathrm{HO}$.

Numerous studies have been performed evaluating different treatment options, such as central stimulating agents, antidiabetic drugs, bariatric surgery, and deep brain stimulation [10-14]. Of these, in particular, antidiabetic glucagon-like peptide-1 (GLP-1) receptor agonists were shown to have potential in reducing weight in adults [15-19]. GLP-1 is one of the two incretin hormones secreted by gut endocrine cells upon ingestion of food. Incretins amplify the secretion of insulin in a glucose-dependent fashion, leading to a two- to threefold greater insulin secretion from orally ingested glucose compared to intravenously administered glucose [20-23]. Furthermore, GLP-1 slows gastric emptying and increases satiety independent of the hypothalamus, leading to a lower food intake [24].

Two trials with GLP-1 receptor agonists have been performed in nonhypothalamic obese children, of which one was a crossover trial that included 12 morbidly obese children between 9 and 16 years old and the other a randomized placebo-controlled trial performed in 22 obese adolescents $[18,19]$. Both found a significant body mass index (BMI) reduction and percent BMI change ( -1.7 and $-2.70 \%$, respectively) after only 3 months of treatment with exenatide. In addition, one case series [15], one open-label pilot study [25], and two adult case reports $[16,17]$ on the use of GLP-1 receptor agonist for HO were published. Of these adult studies, the case series and the first case report showed significant weight loss $(-13.1 \mathrm{~kg} \pm$ SD 5.1 after 24 months and $29 \mathrm{~kg}$ in 2.5 years, respectively) $[15,16]$. The other case report showed significant weight loss as well, with $10.0 \mathrm{~kg}$ after only 4 months. The open-label pilot study found no statistically significant weight loss $[17,25]$. No studies of exenatide treatment in hypothalamic obese children have been published.

With these promising results in mind, we report here our experience with GLP-1 receptor agonist treatment in a small cohort of children with acquired HO, aiming to improve BMI.

\section{Patients and Methods}

\section{Participants}

This case series describes all children treated with GLP-1 agonists at our endocrine clinic between January 2018 and January 2019. Off-label use of GLP-1 (i.e., exenatide) was offered

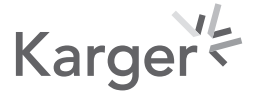


van Schaik et al.: GLP-1 Receptor Agonist for Hypothalamic Obesity

to patients who experienced severe weight gain (defined as a BMI increase $>+1$ standard deviation score [SDS] from diagnosis) and/or obesity (defined by using the BMI criteria of Cole et al. [26]) after treatment for a suprasellar tumor. In addition, children had to be in complete remission of the tumor or to have stable residual disease for $<1$ year. All children had visited a dietician, lifestyle coach, psychologist, or other professional for dietary advice with no or insufficient effect on BMI. Exclusion criteria were age $<5$ years, diabetes mellitus (DM) type 1 , or another known syndrome or disease causing obesity.

\section{Study Procedure}

This was a retrospective analysis of a 1-year intervention. Patients were all administered $2 \mathrm{mg}$ of a sustained-release formation of exenatide subcutaneously (Bydureon; AstraZeneca, Cambridge, UK) once every week for a 12-month period.

\section{Treatment Procedure}

During treatment, patients visited the outpatient clinic pediatric endocrinology unit at least four times per year (at 3, 6, 9, and 12 months after starting therapy). Data on weight, height, and BMI (SDS) in the period before, during (time points 3, 6, 9, and 12 months), and 3 months after treatment were registered and retrieved for this analysis. Weight and height were measured using the same standardized equipment each visit. Weight was rounded off to the nearest $100 \mathrm{~g}$ and height to the nearest millimeter. During all visits, patients were asked about therapy adherence, whether their satiety or hyperphagia had increased or decreased, and whether any change in sleep pattern or physical activity had occurred. Parents and patients were instructed to keep following their regular diet and exercise program during GLP-1 receptor agonist treatment, just as they had been doing before therapy. The dosages of oral hydrocortisone $\left(\mathrm{mg} / \mathrm{m}^{2} /\right.$ day), subcutaneous growth hormone $\left(\mathrm{mg} / \mathrm{m}^{2} /\right.$ day), oral thyroxine $(\mu \mathrm{g} /$ day), and oral dexamphetamine $(\mathrm{mg} /$ day) were collected from before, during, and after treatment.

\section{Adverse Effects}

During the treatment phase, patients were asked whether they experienced any side effects. In addition, blood glucose concentration in the first week every day and thereafter every month were determined to detect hypo- or hyperglycemia. Before start of the exenatide administration, abdominal ultrasounds had been performed on all subjects to evaluate liver steatosis, cholelithiasis, and signs of pancreatitis. Amylase and/or lipase serum concentrations were at least once determined for baseline before or during treatment. Measurements of free thyroxine (FT4) and insulin-like growth factor 1 (IGF-1) were determined every 3 months (time points $3,6,9$, and 12 months after starting therapy).

Complications during exenatide treatment were evaluated and defined as mild (pain or itch after injecting or mild hematoma), moderate (serious pain, rash, or hypoglycemia without loss of consciousness), or severe (hypoglycemia-induced coma or generalized disease, e.g., pancreatitis, gallstones). The diagnosis pancreatitis was defined as either (1) an amylase or lipase value $>3$ times the reference value in patients with clinical suspicion of pancreatitis (severely ill patients with stomach/back pain with unknown cause) or (2) characteristics of pancreatitis on abdominal ultrasound in patients with clinical suspicion of pancreatitis.

\section{Statistical Analysis}

BMI and IGF-1 SDS were calculated using Dutch reference ranges [26-28]. Our primary outcome was the change in BMI SDS over time (corrected for sex and age) between the period of receiving GLP-1 receptor agonist and the period without treatment, which was analyzed by using linear mixed model analysis. The change of weight corrected for height over time

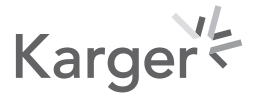


van Schaik et al.: GLP-1 Receptor Agonist for Hypothalamic Obesity

Table 1. Baseline characteristics at the start of treatment

\begin{tabular}{lllllll}
\hline $\begin{array}{l}\text { Patient } \\
\text { No. }\end{array}$ & $\begin{array}{l}\text { Age, } \\
\text { years }\end{array}$ & Diagnosis & $\begin{array}{l}\text { Age at } \\
\text { diagnosis, } \\
\text { years }\end{array}$ & $\begin{array}{l}\text { BMI (SDS) at } \\
\text { tumor diagnosis }\end{array}$ & $\begin{array}{l}\text { Weight (kg) at start of } \\
\text { GLP-1 (SDS corrected } \\
\text { for height) }\end{array}$ & $\begin{array}{l}\text { BMI at start of } \\
\text { GLP-1 (SDS) }\end{array}$ \\
\hline 1 & 18 & CP & 9 & $19.60(1.22)$ & $116.4(4.74)$ & $35.7(3.49)$ \\
2 & 13 & CP & 5 & $21.18(3.04)$ & $109.4(4.01)$ & $42.7(4.29)$ \\
3 & 13 & CP & 5 & $26.60(4.8)$ & $187.7(5.04)$ & $63.5(5.19)$ \\
4 & 18 & CP & 10 & $18.38(0.72)^{\mathrm{a}}$ & $76.7(2.12)$ & $26.0(1.63)$ \\
5 & 15 & SG & 8 & $16.34(0.37)$ & $69.8(2.44)$ & $27.4(2.33)$ \\
\hline
\end{tabular}

BMI, body mass index; CP, craniopharyngioma; GLP-1, glucagon-like peptide-1 receptor agonist; SDS, standard deviation score; SG, suprasellar germinoma. ${ }^{\text {a }}$ BMI at diagnosis could not be retrieved; the BMI presented is 3 years after diagnosis, 8 years before the start of exenatide.

Table 2. Change in BMI SDS over time

\begin{tabular}{lllll}
\hline Patient No. & $\begin{array}{l}\text { BMI SDS at start } \\
(\mathrm{t}=0) \text { of GLP-1 }\end{array}$ & $\begin{array}{l}\text { BMI SDS during } \\
\text { GLP-1 }\end{array}$ & $\begin{array}{l}\text { BMI SDS at stop } \\
\text { of GLP-1 }\end{array}$ & $\begin{array}{l}\text { BMI SDS after } \\
\text { GLP-1 }\end{array}$ \\
\hline 1 & 3.49 & 3.39 & 3.17 & 3.16 \\
2 & 4.29 & 4.41 & 4.39 & 4.41 \\
3 & 5.19 & 5.24 & 5.29 & 5.36 \\
4 & 1.63 & 1.81 & 1.58 & 1.70 \\
5 & 2.33 & 2.00 & 2.50 & 2.36 \\
\hline Total group & $3.39 \pm 1.44$ & $3.38 \pm 1.49$ & $3.39 \pm 1.48$ & $3.40 \pm 1.49$
\end{tabular}

Values are represented as mean \pm standard deviation. BMI, body mass index; GLP-1, glucagon-like peptide-1 receptor agonist; SDS, standard deviation score. ${ }^{a}$ BMI during treatment was measured after a mean period of $13 \pm 1.87$ weeks after starting exenatide. ${ }^{b}$ BMI after treatment was measured after a mean period of $16 \pm 6.36$ weeks after stopping exenatide.

was also analyzed using the same analysis. Having had no treatment was defined as not receiving GLP-1 receptor agonist at least 1 month before measuring anthropometric variables. Having had treatment was defined as having received GLP-1 receptor agonist for at least 1 month before measuring anthropometric variables. No other parameters were included in the linear mixed model analysis. For comparing mean or median values of hormonal supplementation and hormonal serum concentrations between start, during, stop, and after stop of treatment, ANOVA or Kruskal-Wallis test was used, dependent on the test of normality. Statistical analysis was performed using SPSS version 25. A $p$ value of 0.05 was considered significant.

\section{Results}

\section{Baseline Characteristics (Table 1)}

Five patients with a suprasellar tumor were treated with GLP-1 receptor agonist. All patients were female, with a mean age of 15.4 years (range 13.0-18.5). Four patients had been treated for craniopharyngioma, of whom 3 developed HO (around the time of diagnosis or during follow-up). One patient experienced severe weight gain after tumor treatment (weight

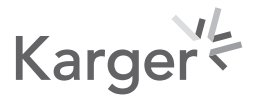


Fig. 1. BMI SDS change before, during, and after treatment with GLP-1 receptor agonist (exenatide) in 5 patients. BMI, body mass index; GLP-1, glucagon-like peptide-1; SDS, standard deviation score.

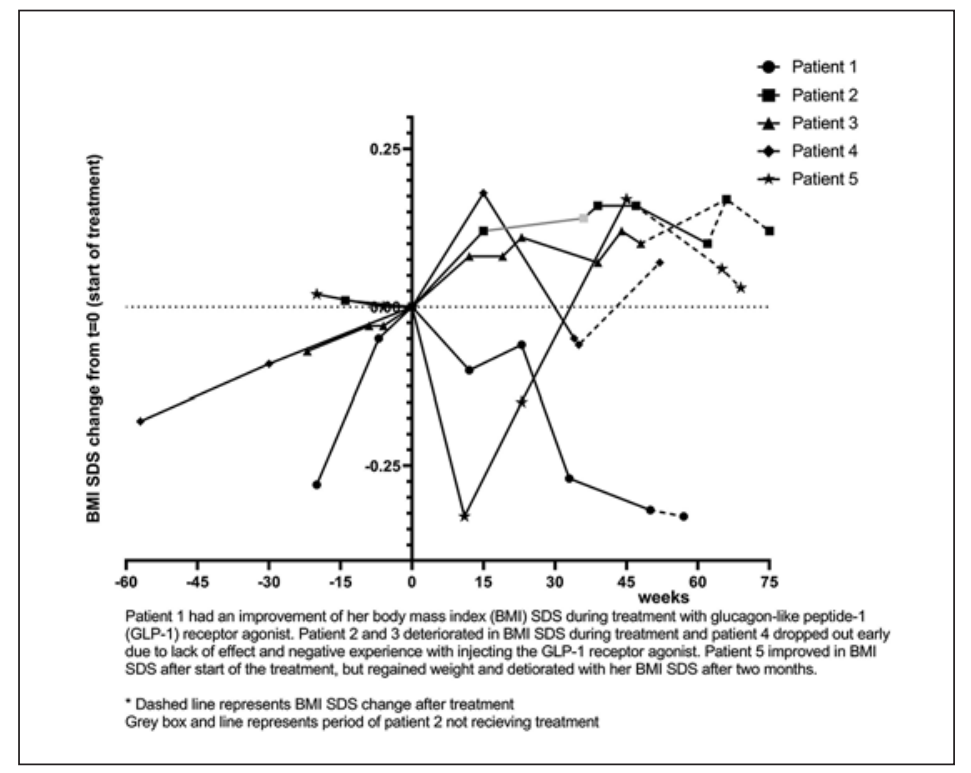

Table 3. Mean concentrations of endocrine parameters and dosages of endocrine substitution therapy

\begin{tabular}{|c|c|c|c|c|c|}
\hline & Mean at start of GLP-1 & Mean during GLP-1 & Mean at stop of GLP-1 & Mean after stop of GLP-1 & $p$ value \\
\hline FT4, pmol/L & $19.20 \pm 1.79$ & $17.18 \pm 1.47$ & $18.25 \pm 4.50$ & $18.42 \pm 3.88$ & 0.558 \\
\hline IGF-1, SDS & $-0.60(-1.46$ to 0.23$)$ & $-1.08(-2.94$ to 0.66$)$ & $0.97(-1.15$ to 1.84$)$ & $-0.60(-2.52$ to 1.46$)$ & 0.510 \\
\hline $\mathrm{GH}, \mathrm{mg} / \mathrm{m}^{2} /$ day & $0.42 \pm 0.32$ & $0.41 \pm 0.34$ & $0.47 \pm 0.37$ & $0.32 \pm 0.41$ & 0.914 \\
\hline $\mathrm{HC}, \mathrm{mg} / \mathrm{m}^{2} /$ day & 8.42 (6.43 to 8.70$)$ & $7.48(4.92$ to 8.66$)$ & 8.20 (4.66 to 8.70$)$ & $8.00(4.62$ to 8.7$)$ & 0.630 \\
\hline Levothyroxine, $\mu \mathrm{g} /$ day & $150.0(87.5$ to 187.5$)$ & 150.0 (87.5 to 187.5$)$ & $150.0(100.0$ to 187.5$)$ & $150.0(125.0$ to 187.5$)$ & 0.953 \\
\hline Dexamphetamine, mg/day $(n=3)$ & $15.0(10.0$ to 30.0$)$ & $10.0(10.0$ to 15.0$)$ & $15.0(10.0$ to 20.0$)$ & $10.0(10.0$ to 15.0$)$ & 0.417 \\
\hline
\end{tabular}

Values are presented as mean \pm standard deviation or median (range). FT4, free thyroxine; GH, growth hormone; GLP-1, glucagon-like peptide-1 receptor agonist; HC, hydrocortisone; IGF-1, insulin-like growth factor 1; SDS, standard deviation score.

for height SDS change from -0.46 to +2.85 at the highest point). The fifth patient developed $\mathrm{HO}$ after treatment for a suprasellar germinoma. All patients had been diagnosed with pituitary dysfunction and central diabetes insipidus for which they used growth hormone, thyroxine, hydrocortisone, and desmopressin. Two out of 5 patients received estrogen supplementation therapy. Three out of 5 patients also used dexamphetamine as a treatment for obesity (median dose $15.0 \mathrm{mg} /$ day [range 10.0-30.0]), with insufficient effect. All 5 patients had been struggling with their weight since tumor diagnosis. Four of the 5 patients had previously been included in a dietary program with extensive coaching the year before starting GLP-1 receptor agonist with no effect on BMI. The other patient had also been actively participating in several dietary programs with insufficient effect. Parents and patients were all very motivated to start a new drug improving BMI.

\section{Primary Outcomes}

The mean BMI of all patients at the start of the intervention with GLP-1 was 39.05 (range 26.02-63.45) and the mean BMI SDS was 3.39 (range 1.63-5.19). The mean BMI at the end of the intervention period was 39.58 (range 26.09-64.64) and the mean BMI SDS was 3.39 (range 1.58-5.29). No statistically significant difference in BMI SDS change could be found when comparing the period of receiving GLP-1 receptor agonist to the period of 
van Schaik et al.: GLP-1 Receptor Agonist for Hypothalamic Obesity

not receiving GLP-1 receptor agonist (BMI SDS change $+0.005,95 \%$ CI -0.07 to $0.08, p=$ 0.892 ) (Table 2; Fig. 1). Also no statistical significant difference in weight change (corrected for height) between the period of receiving GLP-1 receptor agonist to the period of not receiving GLP-1 receptor agonist $(+1.5 \mathrm{~kg}, 95 \% \mathrm{CI}-0.08$ to $3.08, p=0.061)$ was found. Only 1 patient showed weight loss during the intervention with GLP-1 (5.4 kg, BMI -1.85, BMI SDS -0.33).

\section{Secondary Outcomes}

Overall, there was no statistically significant change in mean serum concentrations of FT4, median serum concentrations of IGF-1 SDS, and mean or median daily dosage of growth hormone, hydrocortisone, thyroxine, and dexamphetamine before, during, and after treatment of all 5 patients (Table 3). In the 1 patient with weight loss during GLP-1, an increase in her serum FT4 concentration was noticed from 17 to $22 \mathrm{pmol} / \mathrm{L}$ and also an increase in the IGF-1 SDS concentration from -1.46 to 0.3 , with a simultaneous change in dosage of growth hormone from 0.13 to $0.17 \mathrm{mg} / \mathrm{m}^{2} /$ day.

\section{Effect on Satiety}

Two patients reported an increase in satiety feelings after meals and a decrease in hyperphagia after start of treatment; of these 2 patients 1 lost weight. The other patients noticed no difference in satiety before or during GLP-1 receptor agonist use.

\section{Adverse Effects}

One patient requested to stop exenatide at 8 months and another patient at 11 months of treatment due to lack of effect and negative experience with injecting the GLP-1 receptor agonist. One patient had not injected exenatide from the third month of treatment until the sixth month due to negative experience injecting the GLP-1 receptor agonist. At request of the parent and the patient, the treatment phase was prolonged for 3 months to strive for maximal effect of the GLP-1 receptor agonist.

Two patients experienced mild nausea without vomiting during GLP-1 receptor agonist treatment, which decreased after prolonged use. One other patient reported nausea, vomiting, and diarrhea, but these complaints had already been present before starting the GLP-1 receptor agonist therapy. Four patients experienced pain during injection, leading to decreased therapy adherence or treatment duration in 3 patients. One patient had been hospitalized three times during the year, twice for urinary tract infections and once for obstipation. This patient developed DM type 2 with rising HbA1c concentration from 44 to $54 \mathrm{mmol} / \mathrm{mol}$, for which treatment with metformin was started. In the other patients no hypo- or hyperglycemic events or other adverse events occurred. No changes in amylase or lipase serum concentrations were found during treatment, and no patient experienced pancreatitis.

\section{Discussion}

In this small cohort of young females with acquired HO after treatment for a suprasellar tumor, we found little to no effect of treatment with GLP-1 receptor agonist. When comparing BMI SDS in the period of treatment with GLP-1 receptor agonist in the period without treatment, no significant change in BMI SDS was found (BMI SDS change +0.005 , $95 \% \mathrm{CI}-0.07$ to $0.08, p=0.89$ ). We advise further research to focus on the prevention of $\mathrm{HO}$ and to repeat this study with a larger cohort, preferably in a randomized controlled trial design. 
Of the 5 patients, only 1 developed significant weight loss (5.4 kg, BMI SDS of -0.33 ). All other patients experienced weight gain during treatment with GLP-1, and 1 patient even developed DM type 2 during treatment. Our experience is in contrast with some other reports. Two trials in non-HO morbidly obese children reported significant and clinically relevant results $[18,19]$. The difference in results may be explained by the different etiology of obesity. The widespread distribution of GLP-1 receptors in the brain suggest actions of GLP-1 on widespread brain centers, and in early studies inhibition of food intake after intracerebroventricular as well as direct hypothalamic administration of GLP-1 in rats was described [29, 30]. The fact that GLP-1 receptors are also found in other regions than the hypothalamus is the exact reason why it is believed to be effective in patients with hypothalamic damage. However, as results from recent studies have demonstrated, GLP-1 (administered both centrally, intracerebroventricularly, or peripherally) inhibits ghrelin-stimulated neuronal activity in the hypothalamus as well. This may have played a role in the lack of effectivity of GLP-1 receptor agonists we found in this series of children with hypothalamic damage [31]. This must be further studied.

Simmons et al. [17] reported a 29-kg weight loss in an adult with HO and DM type 2 who was treated with a daily schedule of exenatide. Zoicas et al. [15] found significant weight loss in 8 adults with HO, but 7 of them had already been diagnosed with DM type 2 and all were treated with exenatide $5 \mu \mathrm{g}$ twice daily as well instead of a weekly schedule. It must therefore be considered that a daily schedule of exenatide may have been more effective than the weekly schedule. A recent systematic review, however, with a mixed treatment comparison meta-analysis showed more weight reduction after treatment with exenatide weekly than with a daily schedule in adults with DM type 2 [32]. Additionally, almost all patients received exenatide because of uncontrollable glycemic control, instead of purely for weight control.

It could be argued that our cohort was not given the intervention with GLP-1 at an optimal timing. All children in this study had a follow-up time of 8 years or longer, and some may already have reached a plateau phase in their weight gain [33]. It is unknown whether treatment with GLP-1 receptor agonist earlier in the follow-up or even at diagnosis may be more beneficial to prevent weight gain or stimulate weight loss in these patients. Compared to previous positive reports of GLP-1 in which most of the patients received a GLP-1 receptor agonist after 3 or 4 years, our patients were given GLP-1 receptor agonist after a relative long follow-up time $[15,17]$.

The discomfort that patients experienced during the subcutaneous injections was the reason to stop or pause treatment early in 3 of 5 patients. The lack of effect, already detected by the patients themselves, did not increase the motivation to persist with the weekly subcutaneous injections. However, despite the fact that not all patients fulfilled the 12-month planned intervention, the duration of our intervention does not seem to explain the lack of effect as, when compared to other studies, our observed intervention period was longer than that in most other studies. No other serious side effects or complications of exenatide were found. The reports of nausea were transient and did not lead to a decrease in therapy adherence.

During the intervention period, the use of other medications and changes in hormonal concentrations may have confounded the results in several patients. The one patient who experienced weight loss during GLP- 1 administration was found to have a significantly higher FT4 level at the end of the treatment phase than at the beginning. The thyroid hormones may have influenced her energy expenditure and have positively affected the weight loss. Also, her IGF-1 level had increased. Another patient using dexamphetamine for her HO already from start of the GLP-1 intervention decreased and increased her dexamphetamine dosages during the treatment phase, hoping that the GLP-1 would make the dexamphetamine use needless. 
van Schaik et al.: GLP-1 Receptor Agonist for Hypothalamic Obesity

In another patient, a decrease in the concentration of FT4 during the treatment with GLP-1 from 21 to $13 \mathrm{pmol} / \mathrm{L}$ was found (without reduction of T4 dosage), which may have negatively influenced her weight gain. All of the above situations may have influenced outcome, and yet they are quite illustrative of the complex situation of children with panhypopituitarism and $\mathrm{HO}$.

It is notable that, although not statistical significant, an overall trend towards weight gain was found during GLP-1 administration (increase in weight and BMI SDS) in the treatment phase compared to the period without treatment. It may be argued that without GLP-1 this weight gain would have been even higher, pointing towards a positive effect of GLP-1 in our patients. However, the BMI SDS 3 months after stopping GLP-1 (Table 2) did not increase any further, confirming lack of effect of GLP-1.

The limited number of patients, the lack of males, and the fact that not all patients fulfilled the intended 12-month period are limitations of this report. Ideally, a randomized prospective study should be done to verify these results.

The treatment options for $\mathrm{HO}$ are very limited and recently a new treatment algorithm using six clinical domains was suggested [4]. This stepwise approach may lead to an improved individual treatment program which must be evaluated in the future. In this approach, GLP-1 receptor agonist treatment may be beneficial in selected patients with hyperinsulinism. We had not yet incorporated this new algorithm in the current reported cohort, which may possibly partly explain our negative results. In the future we hope to be able to report more positive results after better characterization of patients and individualizing treatment as suggested by the new algorithm.

In conclusion, in this small cohort, GLP-1 receptor agonist treatment (exenatide) had little to no effect on BMI in children with HO. Due to the fact that HO treatment is disappointing, future research should explore the prevention of $\mathrm{HO}$ and start higher-quality intervention trials with a placebo-controlled design. To make high-quality trials possible, centralization of patents and international collaboration is needed. Hopefully, if specific patients that benefit most from a specific type of treatment are identified, this dramatic situation for the patients can be improved.

\section{Acknowledgements}

The off-label use of the GLP-1 receptor agonist (exenatide) was supported by Wilhelmina Children's Hospital, Utrecht. We want to thank Dr. P. Zuithoff for statistical support.

\section{Statement of Ethics}

The research was conducted ethically in accordance with the World Medical Association Declaration of Helsinki. The Medical Ethical Committee approved the off-label use of GLP-1 receptor agonist (exenatide) in patients with acquired HO. Informed consent for participation and publication of the data was obtained from all parents and patients.

\section{Conflict of Interest Statement}

There is no conflict of interest that could be perceived as prejudicing the impartiality of the research reported.

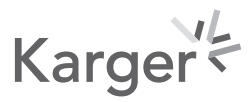


van Schaik et al.: GLP-1 Receptor Agonist for Hypothalamic Obesity

\section{Funding Sources}

The open access article processing charges (APCs) are covered by an UKB-affiliated institution (University of Utrecht, The Netherlands) through an agreement with Karger. The corresponding author is affiliated with the University of Utrecht, The Netherlands.

\section{Author Contributions}

J. van Schaik contributed to the conception and design of the study as well as to the analysis and interpretation of the study, drafted the first manuscript, and critically revised the manuscript. D.G.A. Begijn, E.W. Hoving, and B. Peeters contributed to the analysis and interpretation of the work, drafted the manuscript, and critically revised the manuscript. L. van Iersel and H.M. van Santen contributed to the conception or design of the work as well as to the acquisition, analysis, and interpretation of the study and critically revised the manuscript. Y. Vergeer contributed to the conception and design of the study and critically revised the manuscript. All authors approved the final version to be published and agree to be accountable for all aspects of the work.

\section{References}

1 Honegger J, Barocka A, Sadri B, Fahlbusch R. Neuropsychological results of craniopharyngioma surgery in adults: a prospective study. Surg Neurol. 1998 Jul;50(1):19-28.

2 Müller HL, Gebhardt U, Etavard-Gorris N, Korenke E, Warmuth-Metz M, Kolb R, et al. Prognosis and sequela in patients with childhood craniopharyngioma - results of HIT-ENDO and update on KRANIOPHARYNGEOM 2000. Klin Padiatr. 2004 Nov-Dec;216(6):343-8.

3 Bereket A, Kiess W, Lustig RH, Muller HL, Goldstone AP, Weiss R, et al. Hypothalamic obesity in children. Obes Rev. 2012 Sep;13(9):780-98.

4 van Iersel L, Brokke KE, Adan RA, Bulthuis LC, van den Akker EL, van Santen HM. Pathophysiology and Individualized Treatment of Hypothalamic Obesity Following Craniopharyngioma and Other Suprasellar Tumors: A Systematic Review. Endocr Rev. 2019 Feb;40(1):193-235.

5 Pinkney J, Wilding J, Williams G, MacFarlane I. Hypothalamic obesity in humans: what do we know and what can be done? Obes Rev. 2002 Feb;3(1):27-34.

6 Karavitaki N, Brufani C, Warner JT, Adams CB, Richards P, Ansorge O, et al. Craniopharyngiomas in children and adults: systematic analysis of 121 cases with long-term follow-up. Clin Endocrinol (Oxf). 2005 Apr;62(4): 397-409.

7 Müller HL. Childhood craniopharyngioma. Pituitary. 2013 Mar;16(1):56-67.

8 Heymsfield SB, Avena NM, Baier L, Brantley P, Bray GA, Burnett LC, et al. Hyperphagia: current concepts and future directions proceedings of the 2nd international conference on hyperphagia. Obesity (Silver Spring). 2014 Feb;22(Suppl 1):S1-17.

9 Steinbok P. Craniopharyngioma in children: long-term outcomes. Neurol Med Chir (Tokyo). 2015;55(9): 722-6.

10 van Santen HM, Schouten-Meeteren AY, Serlie M, Meijneke RW, van Trotsenburg AS, Verberne H, et al. Effects of T3 treatment on brown adipose tissue and energy expenditure in a patient with craniopharyngioma and hypothalamic obesity. J Pediatr Endocrinol Metab. 2015 Jan;28(1-2):53-7.

11 Mason PW, Krawiecki N, Meacham LR. The use of dextroamphetamine to treat obesity and hyperphagia in children treated for craniopharyngioma. Arch Pediatr Adolesc Med. 2002 Sep;156(9):887-92.

12 Hamilton JK, Conwell LS, Syme C, Ahmet A, Jeffery A, Daneman D. Hypothalamic Obesity following Craniopharyngioma Surgery: Results of a Pilot Trial of Combined Diazoxide and Metformin Therapy. Int J Pediatr Endocrinol. 2011;2011(1):417949.

13 Rottembourg D, O'Gorman CS, Urbach S, Garneau PY, Langer JC, Van Vliet G, et al. Outcome after bariatric surgery in two adolescents with hypothalamic obesity following treatment of craniopharyngioma. J Pediatr Endocrinol Metab. 2009 Sep;22(9):867-72.

14 Harat M, Rudaś M, Zieliński P, Birska J, Sokal P. Nucleus accumbens stimulation in pathological obesity. Neurol Neurochir Pol. 2016;50(3):207-10.

15 Zoicas F, Droste M, Mayr B, Buchfelder M, Schöfl C. GLP-1 analogues as a new treatment option for hypothalamic obesity in adults: report of nine cases. Eur J Endocrinol. 2013 Apr;168(5):699-706. 
van Schaik et al.: GLP-1 Receptor Agonist for Hypothalamic Obesity

16 Thondam SK, Cuthbertson DJ, Aditya BS, Macfarlane IA, Wilding JP, Daousi C. A glucagon-like peptide-1 (GLP-1) receptor agonist in the treatment for hypothalamic obesity complicated by type 2 diabetes mellitus. Clin Endocrinol (Oxf). 2012 Oct;77(4):635-7.

17 Simmons JH, Shoemaker AH, Roth CL. Treatment with glucagon-like Peptide-1 agonist exendin-4 in a patient with hypothalamic obesity secondary to intracranial tumor. Horm Res Paediatr. 2012;78(1):54-8.

18 Kelly AS, Metzig AM, Rudser KD, Fitch AK, Fox CK, Nathan BM, et al. Exenatide as a weight-loss therapy in extreme pediatric obesity: a randomized, controlled pilot study. Obesity (Silver Spring). 2012 Feb;20(2):364-70.

19 Kelly AS, Rudser KD, Nathan BM, Fox CK, Metzig AM, Coombes BJ, et al. The effect of glucagon-like peptide-1 receptor agonist therapy on body mass index in adolescents with severe obesity: a randomized, placebocontrolled, clinical trial. JAMA Pediatr. 2013 Apr;167(4):355-60.

20 Knop FK, Vilsbøll T, Højberg PV, Larsen S, Madsbad S, Vølund A, et al. Reduced incretin effect in type 2 diabetes: cause or consequence of the diabetic state? Diabetes. 2007 Aug;56(8):1951-9.

21 Holst JJ. On the physiology of GIP and GLP-1. Horm Metab Res. 2004 Nov-Dec;36(11-12):747-54.

22 Holst JJ, Vilsbøll T, Deacon CF. The incretin system and its role in type 2 diabetes mellitus. Mol Cell Endocrinol. 2009 Jan;297(1-2):127-36.

23 Shaefer CF Jr, Kushner P, Aguilar R. User's guide to mechanism of action and clinical use of GLP-1 receptor agonists. Postgrad Med. 2015;127(8):818-26.

24 Willms B, Werner J, Holst JJ, Orskov C, Creutzfeldt W, Nauck MA. Gastric emptying, glucose responses, and insulin secretion after a liquid test meal: effects of exogenous glucagon-like peptide-1 (GLP-1)-(7-36) amide in type 2 (noninsulin-dependent) diabetic patients. J Clin Endocrinol Metab. 1996 Jan;81(1):327-32.

25 Lomenick JP, Buchowski MS, Shoemaker AH. A 52-week pilot study of the effects of exenatide on body weight in patients with hypothalamic obesity. Obesity (Silver Spring). 2016 Jun;24(6):1222-5.

26 Cole TJ, Bellizzi MC, Flegal KM, Dietz WH. Establishing a standard definition for child overweight and obesity worldwide: international survey. BMJ. 2000 May;320(7244):1240-3.

27 Schönbeck Y, Talma H, van Dommelen P, Bakker B, Buitendijk SE, Hirasing RA, et al. Increase in prevalence of overweight in Dutch children and adolescents: a comparison of nationwide growth studies in 1980, 1997 and 2009. PLoS One. 2011;6(11):e27608.

28 Schönbeck Y, Talma H, van Dommelen P, Bakker B, Buitendijk SE, HiraSing RA, et al. The world's tallest nation has stopped growing taller: the height of Dutch children from 1955 to 2009. Pediatr Res. 2013 Mar; 73(3): 371-7.

29 Göke R, Larsen PJ, Mikkelsen JD, Sheikh SP. Distribution of GLP-1 binding sites in the rat brain: evidence that exendin-4 is a ligand of brain GLP-1 binding sites. Eur J Neurosci. 1995 Nov;7(11):2294-300.

30 Schick RR, Walde TV, Zimmermann JP, Schusdziarra V, Classen M. Glucagon-Like Peptide (Glp)-1-(7-36)Amide Suppresses Food-Intake in Fasted Rats at Hypothalamic Sites. Gastroenterology. 1993;104(4):A853.

31 Riediger T, Eisele N, Scheel C, Lutz TA. Effects of glucagon-like peptide 1 and oxyntomodulin on neuronal activity of ghrelin-sensitive neurons in the hypothalamic arcuate nucleus. Am J Physiol Regul Integr Comp Physiol. 2010 Apr;298(4):R1061-7.

32 Potts JE, Gray LJ, Brady EM, Khunti K, Davies MJ, Bodicoat DH. The Effect of Glucagon-Like Peptide 1 Receptor Agonists on Weight Loss in Type 2 Diabetes: A Systematic Review and Mixed Treatment Comparison MetaAnalysis. PLoS One. 2015 Jun;10(6):e0126769.

33 Sterkenburg AS, Hoffmann A, Gebhardt U, Warmuth-Metz M, Daubenbüchel AM, Müller HL. Survival, hypothalamic obesity, and neuropsychological/psychosocial status after childhood-onset craniopharyngioma: newly reported long-term outcomes. Neuro Oncol. 2015 Jul;17(7):1029-38. 